\title{
Nonylphenol mass transfer from field-aged sediments and subsequent biodegradation in reactors mimicking different river conditions
}

\author{
Jasperien de Weert • Marta Streminska • Dong Hua • \\ Tim Grotenhuis • Alette Langenhoff • Huub Rijnaarts
}

Received: 28 May 2009/Accepted: 27 September 2009 /Published online: 27 November 2009

(C) The Author(s) 2009. This article is published with open access at Springerlink.com

\begin{abstract}
Purpose Sediments can function as secondary source for water pollution of aerobically biodegradable nonhalogenated organic compounds, which are persistent in anaerobic sediments. The mass transfer of compounds from sediment to bulk water depends on hydraulic conditions. In this study, desorption, mass transfer and biodegradation are investigated under settled and resuspended sediment conditions for branched nonylphenol (NP), which was used as model compound for aerobically biodegradable and anaerobic persistent compounds.

Materials and methods Continuous flow through reactor experiments were performed in duplicate with aged NP polluted sediment under sterile and non-sterile conditions to investigate the mass transfer and combined mass transfer and biodegradation.

Results and discussion The mass transfer of NP from the sediment bed to the bulk water decreased from $5.1 \pm$ $0.6 \mu \mathrm{g} \mathrm{d}^{-1}$ to a stable value of $0.3 \pm 0.02 \mu \mathrm{g} \mathrm{d}^{-1}$. The desorbed NP in the non-sterile reactors was biodegraded in the first 20 days of the experiment. At the end of the settled sediment conditions, the biodegradation became very limited, and the mass transfer was comparable to the mass transfer under sterile conditions. Upon resuspension, the
\end{abstract}

Responsible editor: Thomas Knacker

J. de Weert $(\square) \cdot$ M. Streminska $\cdot$ A. Langenhoff $\cdot$ H. Rijnaarts

TNO/Deltares Subsurfaces and Groundwater Systems,

Princetonlaan 6,

3584 CB Utrecht, The Netherlands

e-mail: jasperien.deweert@deltares.nl

J. de Weert $\cdot$ D. Hua $\cdot$ T. Grotenhuis

Section of Environmental Technology, Wageningen University,

Bomenweg 2,

6703 HD Wageningen, The Netherlands
NP concentration in the bulk water increased instantaneously in all reactors with a factor of 100 . This immediate, increased mass transfer of NP from the sediment was larger than the amount that can be biodegraded under optimal conditions. Under non-sterile conditions, a second increase in the mass transfer was observed. However, the amount of desorbing NP during this second increase in mass transfer can be biodegraded under optimal environmental conditions.

Conclusions NP desorbs continuously at low concentrations from the sediment bed into the bulk water, which can almost be completely biodegraded. Resuspension of NP-polluted sediment initially led to an increase in the desorbing NP concentrations and can be followed by a subsequent reduction of the concentrations due to biodegradation under environmental conditions where biodegradation of NP can occur.

Keywords Mass transfer $\cdot$ Nonylphenol $\cdot$ Resuspended sediment $\cdot$ Sediment bed

\section{Introduction}

River basins contain many xenobiotic compounds, which can be toxic for the organisms in the aquatic environment. Depending on their chemical properties, these chemicals are either dissolved or adsorbed to sediment particles and suspended matter. In the case of strong adsorption, sediment or suspended particles scavenge pollutants out of the water phase. Settling of these particles results in pollutants sinking in the beds of rivers, lakes and estuaries. These sinks may change into sources for water contamination when the compound desorbs from the sediment under changes in river conditions, such as the increase in 
turbulence of the river water. These changes can be caused by seasonal effects, extreme rainfall combined with peak river discharges (Gibson et al. 2005), or nautical and dredging activities. Changing hydraulic regimes of rivers, like the change from calm low-flow conditions to turbulent high-flow conditions, can result in resuspension of sediment particles into the river water. Then, adsorbed compounds can be released into the water phase and become more available for uptake by aquatic organisms posing renewed ecotoxicological hazard to aquatic life. However, in this situation, pollutants also become more available for biodegradation that can decrease the amount of desorbed compounds in the water phase. When the rate of biodegradation in the aerobic river water is higher than the rate of desorption, the compounds are generally biodegraded in the sediment-river water interphase and will not reach the bulk water. This results in a limited hazard for the organisms in the aquatic environment. For adequate prediction of the fate of pollutants and the ecological effects of polluted sediments in river basins, these effects of changing conditions on desorption and biodegradation processes need to be better understood and taken into account.

Sediment beds are mainly anoxic with a thin aerobic layer of only a few millimetres at the interphase with the aerobic surface water (Huttunen et al. 2006; Martin et al. 1998; Middeldorp et al. 2003). When chemicals move from the anaerobic sediment to the aerobic river water or vice versa, the changed biogeochemical conditions affect their fate. Most heavy metals are immobilised in anaerobic sediments (Vink 2002; Vink et al. 2009). This immobilisation improves the chemical and ecological quality of water systems. However, metals become mobilised again when sediments are resuspended in aerobic surface water. Biodegradation rates of highly halogenated organic compounds, like polychlorinated biphenyls and hexachlorobenzenes, are higher in anaerobic organic rich sediments compared with degradation under aerobic conditions (Brown et al. 1987; Mohn and Tiedje 1992). Therefore, storage and natural attenuation (naturally occurring biodegradation) of these halogenated compounds in anaerobic sediments can reduce their bioavailability and concentration, respectively. Many non-halogenated hydrophobic organic pollutants, like poly aromatic hydrocarbons, petroleum hydrocarbons and natural hormones are less or nonbiodegradable under anoxic conditions (de Mes et al. 2005; Vermeulen et al. 2003). Storage of these non-halogenated organic compounds in anaerobic sediments slows down or even stops their biodegradation, thus creating a long-lasting potential source of pollution for the aquatic ecosystem in the future.

This study focuses on the fate of branched nonylphenol (NP) during changing resuspension conditions. Branched nonylphenol was used as model compound for aerobically biodegradable non-halogenated organic pollutants that are persistent under anaerobic conditions, because (1) it is a pollutant found in many river systems (Bennie et al. 1997; Heemken et al. 2001; Navarro et al. 2009; Wu et al. 2007), (2) it can cause toxicological effects on aquatic biota because of its estrogenic activity, although concentrations are mainly present below effect concentrations (Soares et al. 2008), (3) it adsorbs to and desorbs from sediments (de Weert et al. 2008), and (4) is biodegradable under aerobic conditions, but persistent under anaerobic conditions (Corvini et al. 2006).

Pollutant mass transfer from the anaerobic sediment through the interphase between the sediment and the water to the aerobic bulk water is mainly driven by the concentration gradient between the sediment particle and the surrounding water and is affected by the sedimentwater contact area (Birdwell et al. 2007; Cheng et al. 1995). The total mass transfer $\Phi_{\text {sed }}\left[\mu \mathrm{g} \mathrm{d}^{-1}\right]$ from the sediment to the bulk water can be described by the following equation:

$\Phi_{\text {sed }}=k \times A_{\text {sed }} \times\left(C_{\text {sur }}-C_{\mathrm{bw}}\right)$

$\Phi_{\text {sed }} \quad \operatorname{mass}$ flux $\left[\mu \mathrm{g} \mathrm{d}^{-1}\right]$

$k \quad$ overall mass transfer coefficient $\left[\mathrm{m} \mathrm{d}^{-1}\right]$

$A_{\text {sed }}$ the contact surface of the sediment and the surrounding water $\left[\mathrm{m}^{2}\right]$

$C_{\text {sur }}$ concentration at the solid surface $\left[\mu \mathrm{g} \mathrm{m}^{-3}\right]$

$C_{\mathrm{bw}}$ the concentration in the bulk water $\left[\mu \mathrm{g} \mathrm{m}^{-3}\right]$

From this equation, it can be seen that there is a flux from the sediment to the bulk water when the concentration at the solid surface $\left(C_{\text {sur }}\right)$ is larger than the concentration in the bulk water $\left(C_{\mathrm{bw}}\right)$. Thus, the sediment will act as a source for water pollution. The contact area enlarges during resuspension, and this enlarges the mass transfer, followed by an increased rate of NP desorption. Biodegradation of the desorbed NP can reduce the ecotoxicological effects of this compound (de Weert et al. 2008). However, if the biodegradation rate is lower than the desorption rate, the pollutant will remain at elevated concentrations in the water phase after resuspension, where it can cause ecotoxicological effects.

Understanding of the interaction between sorption, mass transfer and biodegradation under changing resuspension conditions is needed for a quantitative prediction of the toxicological effects in rivers. Therefore, the above-mentioned processes were studied for our model compound NP under two different conditions, namely (1) settling sediment conditions and (2) resuspended sediment conditions, as schematically presented in Fig. 1. A river has a low water flow velocity during settling 
Fig. 1 Conceptual model for exchange processes of hydrophobic chemicals dissolved in the river water and sorbed to sediments under a settling sediment conditions with low resuspension and high settling of the sediment and $\mathbf{b}$ resuspended sediment conditions. se settling, re resuspension

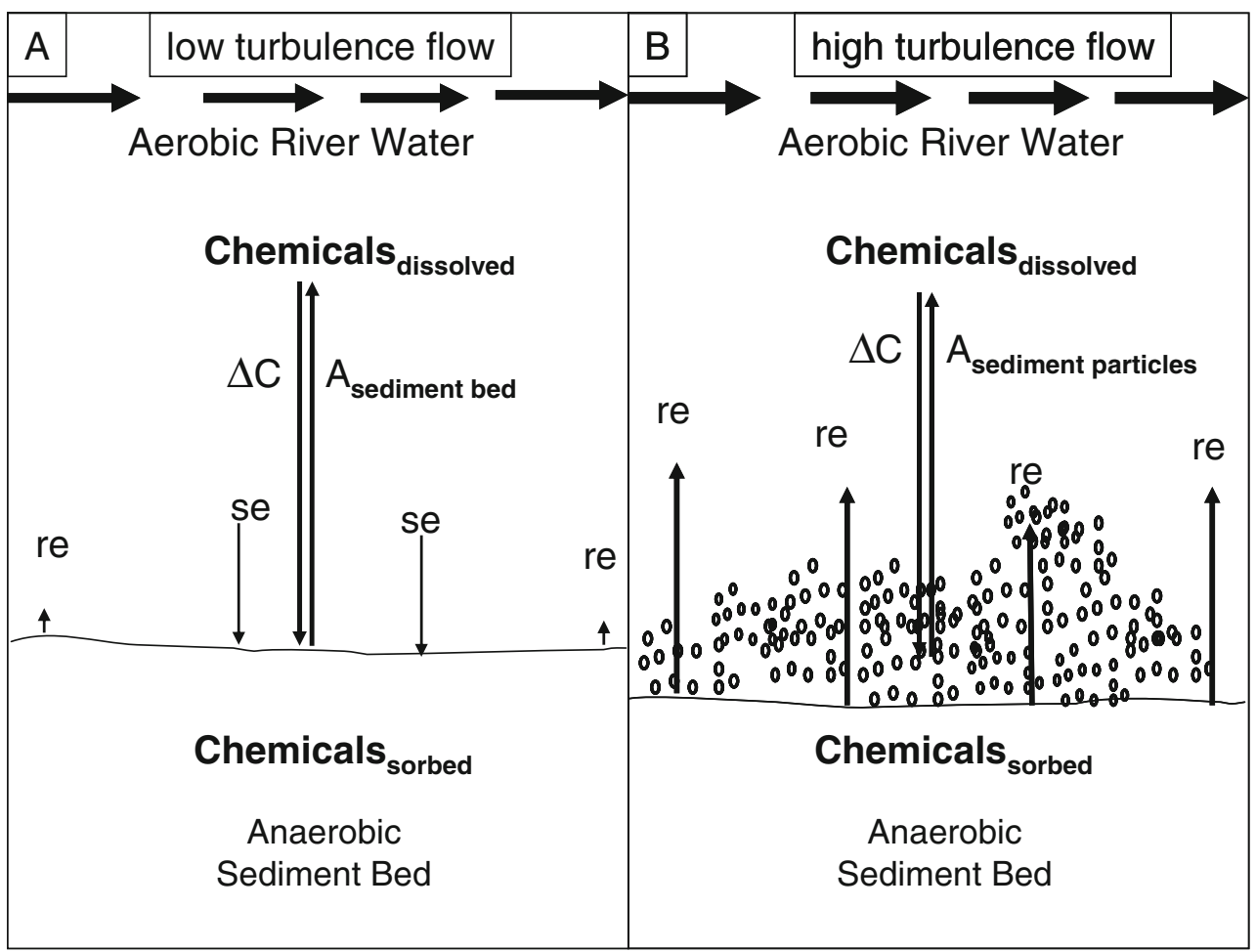

sediment conditions without resuspension. The sediment is predominantly present as a sediment bed, and the area of the sediment bed $\left(A_{\text {sed }}\right)$ controls the mass transfer from the sediment to the bulk water. Biodegradation of the desorbing NP can only occur in the aerobic bulk water and at the interphase with the sediment bed. During resuspended sediment conditions, a vast amount of sediment particles is resuspended into the bulk water. Under this condition, the desorption area $A_{\text {sed }}$ becomes enlarged compared with the desorption area of the sediment bed. As a result, the mass transfer of NP into the bulk water will be enhanced, resulting in higher NP concentrations in the bulk water. On the other hand, biodegradation may be stimulated upon resuspension as the redox conditions will shift to aerobic. This stimulation of biodegradation can reduce the risk of ecological effects and uptake in the food chain.

In this study, quantitative desorption and biodegradation of NP were determined using aged NP-polluted sediment. Continuous reactor experiments were conducted to mimic changing mass transfer conditions in a river system.

\section{Materials and methods}

\subsection{Chemicals and materials}

Tenax ${ }^{\circledR}$-TA (20-35 mesh, pre-cleaned) was purchased from Buchem B.V. (Apeldoorn, the Netherlands). Petroleum ether $40-60^{\circ} \mathrm{C}$ ( $\geq 90 \%$ purity) and acetone (HPLC grade) were obtained from Merck (Darmstadt, Germany). A nonylphenol technical mixture ( $>94 \%$ purity) for calibration standards was purchased from Riedel de Haën (Seelze, Germany). Other used chemicals were of the highest purity available and were used without further purification. All glassware and microwave tubes were pre-cleaned by washing three times with acetone and two times with petroleum ether.

\subsection{Sediment}

Sediment with $20 \mathrm{mg} \mathrm{kg}^{-1}$ dry weight (dw) NP was collected in June 2005, from the Huerva river, a tributary of the Ebro river in Spain. The sampling location was located on the boundary of the city Zaragoza (Spain, $41^{\circ} 37^{\prime} 23^{\prime \prime} \mathrm{N}$, $\left.0^{\circ} 54^{\prime} 28^{\prime \prime} \mathrm{W}\right)$. Sediment samples were taken with stainless steel cores to a 50-cm depth and collected in a 10-1 vessel. The vessel was completely filled with sediment to avoid a gaseous head space and was transported on ice to the laboratory. The sediment was sieved at mesh $<2 \mathrm{~mm}$ in the laboratory and stored at $4^{\circ} \mathrm{C}$ for 2 years until use. The NP in the sediment consisted of a mixture of branched isomers as analysed by gas chromatography/mass spectrometry, and the single isomers were not identified. Previous experiments showed that $95 \%$ of the NP in this sediment was potentially available and could be biodegraded under aerobic conditions (de Weert et al. 2008). The TOC content of the sediment was $3.5 \%$ as determined by Al-West 
(Deventer, the Netherlands). The dry matter content was determined by drying the sediment overnight at $105^{\circ} \mathrm{C}$. The organic matter content was $8.4 \%$, determined gravimetrically by combustion of dried samples for $6 \mathrm{~h}$ at $550^{\circ} \mathrm{C}$. The sediment contained two main particle size fractions, namely $<32 \mu \mathrm{m}(52 \%)$ and $32-125 \mu \mathrm{m}(34 \%)$. These fractions were determined by sieving with Retsch sieves with mesh sizes of 32,125 and $500 \mu \mathrm{m}$ and by using a Beckman Coulter LS 230 laser diffraction particle size analyzer with polarisation intensity differential of scattered light (PIDS). The Fraunhofer theory of light scattering was used to calculate the particle size distribution. Prior to particle size analysis, sediment samples were dispersed in demineralized water and thoroughly mixed. The injected slurry volume was controlled to obtain a total obscuration level of $10 \pm 3 \%$ and a PIDS obscuration of $50 \pm 10 \%$ (Buurman et al. 1997).

\subsection{Reactor setup}

Desorption from the polluted sediment and aerobic biodegradation of NP were studied in duplicate in a reactor setup that mimics changing resuspension conditions in a river system (Fig. 2), based on the setup as described by Smit et al. (Smit et al. 2008). Non-mixing and mixing conditions were studied in duplicate under both sterile and non-sterile conditions. Before the start of the experiment, the reactors were rinsed with acetone and petroleum ether and autoclaved at $121{ }^{\circ} \mathrm{C}$ for $15 \mathrm{~min}$. Thereafter, the reactors were filled with $100 \mathrm{~g}$ sediment (wet weight) and $650 \mathrm{ml}$ minimal mineral medium. Minimal mineral medium was used because a large volume was needed during the experiments, which made the use of river water practically impossible. The used medium was a standard minimal medium used for biodegradation experiments and was prepared as described in Tros et al., but without $\mathrm{Na}_{2} \mathrm{SeO}_{3} \cdot 5 \mathrm{H}_{2} \mathrm{O}$ (Tros et al. 1996). The medium was not optimised to promote biodegradation of NP. To establish a sediment bed, the sediment was shortly mixed with the medium before the start of the experiment. The influent was pumped into the reactor (approximately $1 \mathrm{ld}^{-1}$ ) just above the surface of the sediment, and the effluent was pumped from the liquid surface with a glass tube with the same pumping rate as the influent (see Fig. 2). Only liquid was removed from the reactor, and the sediment remained permanently in the reactor. The hydraulic retention time of the medium in the reactors was approximately $15 \mathrm{~h}$. The effluent was pumped from the medium surface via the glass tube through a glass column with approximately $0.6 \mathrm{~g}$ Tenax. The glass column contained a glass filter beneath and a $21-\mu \mathrm{m}$ stainless steel filter with a thickness $<0.5 \mathrm{~mm}$ on top of the Tenax, to keep the Tenax in the glass column. The effluent passed the Tenax, where NP in the effluent sorbed to the Tenax. After passing through the Tenax, the effluent was pumped into a waste vessel. The Tenax in the columns was refreshed at selected times during the experiments. Before the refreshment of the Tenax, 15-ml effluent samples were taken to control the efficiency of the Tenax extraction of the NP from the water phase. During the change of the Tenax, the pump was switched off for 1-2 min for practical reasons. With the Tenax, the absolute desorbed amount of NP was determined. The concentration in the water phase was calculated with the absolute amount of NP and the volume of medium that had passed through the Tenax.

Sediment samples ( $2 \mathrm{~g} \mathrm{dw}$ ) were taken to determine the NP concentration in the sediment before the start and at the
Fig. 2 Schematic setup of the duplicate reactors

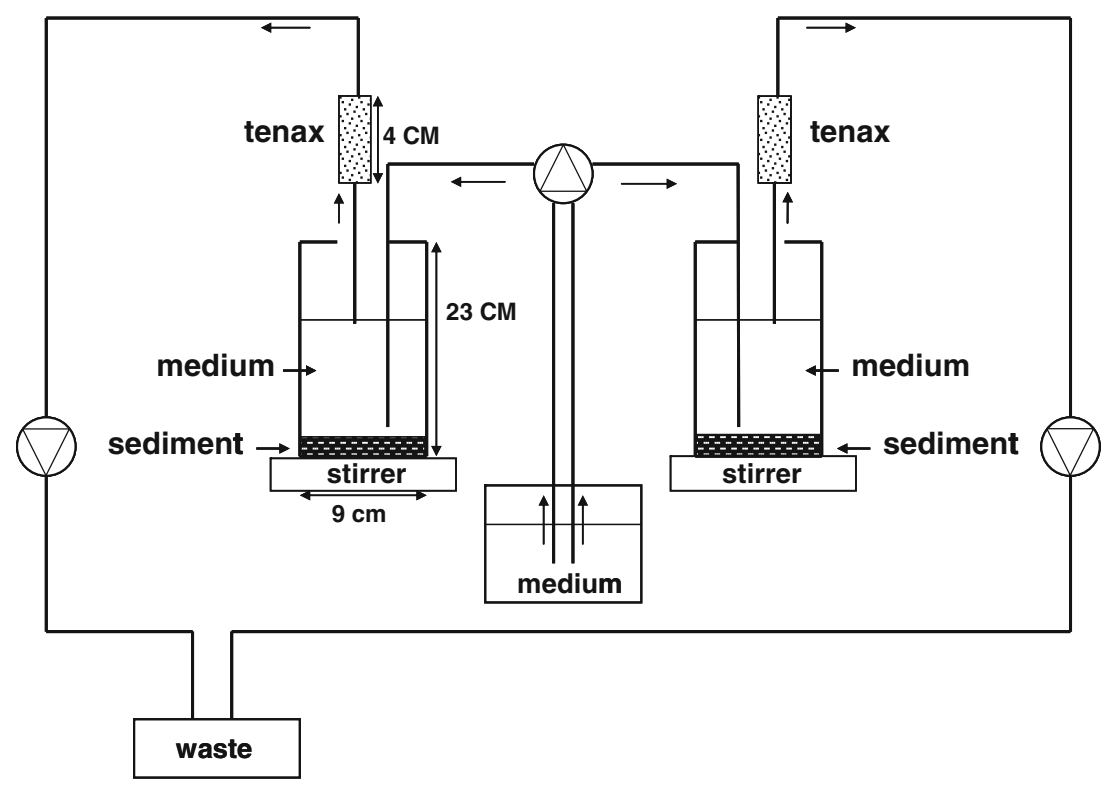


end of the experiments. All experiments were performed at $20^{\circ} \mathrm{C}$, and during the experiments, the dissolved oxygen in the water phase, as well as in the sediment was measured with an OX-500 micro-electrode (Unisense, Aarhus, Denmark). The experiment lasted for 59 days and was divided in four parts. The settling sediment condition was maintained in the first 35 days of the experiment, simulating a gently flowing river (part I). The sediment was not mixed with the medium, and a sediment bed was formed with a bed thickness of approximately $2.5 \mathrm{~cm}$. Thereafter, the experiment continued with the resuspended sediment condition for 14 days (part IIa and IIb). Part IIa contained the results of the first 2 to 4 days of the resuspended sediment period and part IIb the results of the remaining resuspended sediment period. During the resuspended sediment condition, the sediment was only resuspended and the flow rate was not changed. The sediment and medium were mixed for 5 min every $8 \mathrm{~h}$. During the mixing, the pumps were switched off to avoid removal of sediment from the reactor. The sediment was allowed to settle for $25 \mathrm{~min}$ before the pumps were switched on again. After the mixing period of 14 days, the reactors were operated for another 9 days at the original settling sediment conditions (part III).

Table 1 shows the experimental conditions. A flow of $0.7 \mathrm{ml} \mathrm{min} \mathrm{m}^{-1}$ was established to avoid washing out the microorganisms and to let them be able to grow. A sterile experiment was performed in duplicate (reactor 1 and reactor 2) to study the desorption behaviour of NP from the sediment. To inhibit microbial activity, $\mathrm{HgCl}_{2}\left(50 \mathrm{mg} \mathrm{l}^{-1}\right)$ was added to the medium. The combination of desorption and biodegradation of NP from the sediment was studied in the non-sterile experiment (reactor 3 and reactor 4). One of the duplicates of the non-sterile reactors (reactor 4) was started 1 day later due to technical reasons. However, the mixing period started at the same day, and the period with the sediment bed was therefore 35 days in reactor 3 and 34 days in reactor 4 .

\subsection{Biodegradation of NP in batch experiments}

The biodegradation of the NP in the sediment was studied in batch experiments with the mineral medium under optimal conditions to determine the biodegradation rate. Degradation was also studied with aerobic river water. For this purpose, river water samples were taken in dark glass bottles at the same location and the same time as the sediment samples were collected (Section 2.2). These water samples were transported to the laboratory on ice and stored at $4^{\circ} \mathrm{C}$ for 2 years until use. The degradation tests of NP were performed in triplicate including one sterile control. Volumes of $50 \mathrm{ml}$ mineral medium or $50 \mathrm{ml}$ river water and $5 \mathrm{~g}$ wet sediment ( $2 \mathrm{gdw})$ were added to $250-\mathrm{ml}$ bottles, which were closed with a viton stopper. The bottles were incubated at $20^{\circ} \mathrm{C}$ and horizontally shaken in the dark. The NP concentration was measured at various time intervals by taking $200 \mu \mathrm{l}$ of slurry sample from the bottles. The samples were analysed for NP concentrations by GC-MS with solid phase micro-extraction (SPME) (de Weert et al. 2008).

\subsection{Mass transfer calculations}

The following mass balance was used to calculate the average mass transfer $(\Phi)$ in a certain time interval in the sterile experiment without biodegradation:

$V \times \mathrm{d} C / \mathrm{d} t=\Phi-\varphi \times C$

$V \quad$ Volume medium in reactor $\left[\mathrm{m}^{3}\right]$

$C$ Concentration in bulk water $\left[\mu \mathrm{g} \mathrm{m}^{-3}\right]$

$t$ time [days]

$\Phi$ mass transfer $\left[\mu \mathrm{g} \mathrm{d}^{-1}\right]$

$\varphi \quad$ flow $\left[\mathrm{m}^{3} \mathrm{~d}^{-1}\right]$

The following mass balance includes biodegradation and is used for the non-sterile experiment:

$V \times \mathrm{dC} / \mathrm{d} t=\Phi-\varphi \times C-V \times k \times C$

$V \quad$ Volume medium in reactor $\left[\mathrm{m}^{3}\right]$

C Concentration in bulk water $\left[\mu \mathrm{g} \mathrm{m}^{-3}\right]$

$t$ time [days]

$\Phi \quad$ mass transfer $\left[\mu \mathrm{g} \mathrm{d}^{-1}\right]$
Table 1 Experimental conditions of the reactors during the sterile (reactors 1 and 2) and non-sterile experiments (reactors 3 and 4)

\begin{tabular}{lccccc}
\hline Experimental conditions & \multicolumn{2}{l}{ Sterile } & & \multicolumn{2}{l}{ Non-sterile } \\
\cline { 2 - 3 } \cline { 5 - 6 } & Reactor 1 & Reactor 2 & & Reactor 3 & Reactor 4 \\
\hline Sediment $\left(\mathrm{mg} \mathrm{ug}^{-1}\right)$ & 41.5 & 41.5 & & 37.3 & 37.3 \\
NP $S_{0}\left(\mathrm{mg} \mathrm{ug}^{-1} \mathrm{dw}\right)$ & $22.6 \pm 1.5$ & $22.6 \pm 1.5$ & & $19.1 \pm 0.58$ & $19.1 \pm 0.58$ \\
Medium volume $(\mathrm{ml})$ & 649 & 653 & & 651 & 680 \\
Flow $\left(\mathrm{mol} \mathrm{min}^{-1}\right)$ & 0.70 & 0.63 & & 0.68 & 0.64 \\
\hline
\end{tabular}


$\varphi \quad$ flow [cubic meter per day]

$k$ first-order degradation rate constant [per day]

Equation 3 assumes that the degradation of NP, expressed with the product $\mathrm{V} \times \mathrm{k} \times \mathrm{C}$, takes place in the whole reactor volume, and is valid for fully resuspended sediment conditions. During the settled sediment conditions, degradation can only take place at the interphase of the sediment and bulk water. Since the volume of the active layer is unknown, this mass balance is not used for the calculation of the average mass transfer in the nonsterile reactor experiment under the settling sediment conditions.

\subsection{Pore water concentrations}

In the inner part of the sediment bed, NP was present in the pore water and adsorbed to the sediment particles. As equilibrium in the sediment bed is assumed, the pore water concentration can be calculated with:

$K_{\mathrm{d}}=C_{\mathrm{sed}} / C_{\mathrm{pw}}$

$K_{\mathrm{d}} \quad$ the partitioning coefficient between the concentration in the sediment $\left[1 \mathrm{~kg}^{-1}\right]$

$C_{\text {sed }}$ concentration in the sediment $\left[\mathrm{mg} \mathrm{kg}^{-1}\right]$

$C_{\text {pw }}$ concentration in the pore water $\left[\mathrm{mg} \mathrm{l}^{-1}\right]$

2.7 Nonylphenol extraction, chemical analysis and statistics

Both Tenax samples and sediment samples were collected in 20-ml vials with $10 \mathrm{ml}$ acetone. The vials were closed with a polytetrafluoroethylene/butyl rubber septum and stored at $-20^{\circ} \mathrm{C}$ before extraction. The NP was extracted from the Tenax or sediment samples by microwave extractions with acetone and petroleum ether. Before extraction, another $5 \mathrm{ml}$ acetone and $15 \mathrm{ml}$ petroleum ether were added to the Tenax and sediment samples. The petroleum ether extracts were analysed by GC-MS as previously described (de Weert et al. 2008). The detection limit of NP in the petroleum ether extracts was $100 \mu \mathrm{g} \mathrm{l^{-1 }}$.

For the analyses of NP concentrations in the effluent, $2 \mathrm{ml}$ effluent was added to a 20-ml headspace vial. The headspace vial was capped with a magnetic crimp cap with blue silicon and Teflon-coated septum (Grace Davison Discovery Science, Deerfield, Il, USA) and analysed with GC-MS by solid phase micro-extractions as previously described (de Weert et al. 2008).
Student's $t$ tests were used for comparison of the nonylphenol concentration, and the probability of significance was set at $p<0.05$.

\section{Results and discussion}

\subsection{NP concentrations during experiment}

\subsubsection{Sterile experiment}

Initially, in part I of the sterile experiment, the NP concentration in the bulk water was 5.8 and $5.5 \mu \mathrm{g} \mathrm{l^{-1 }}$ in reactors 1 and 2, respectively, due to addition of the sediment to the reactors, followed by stirring of the sediment and the medium (Fig. 3a). The stirring stopped shortly after the additions of the sediment; the NP concentration decreased in both sterile reactors. The
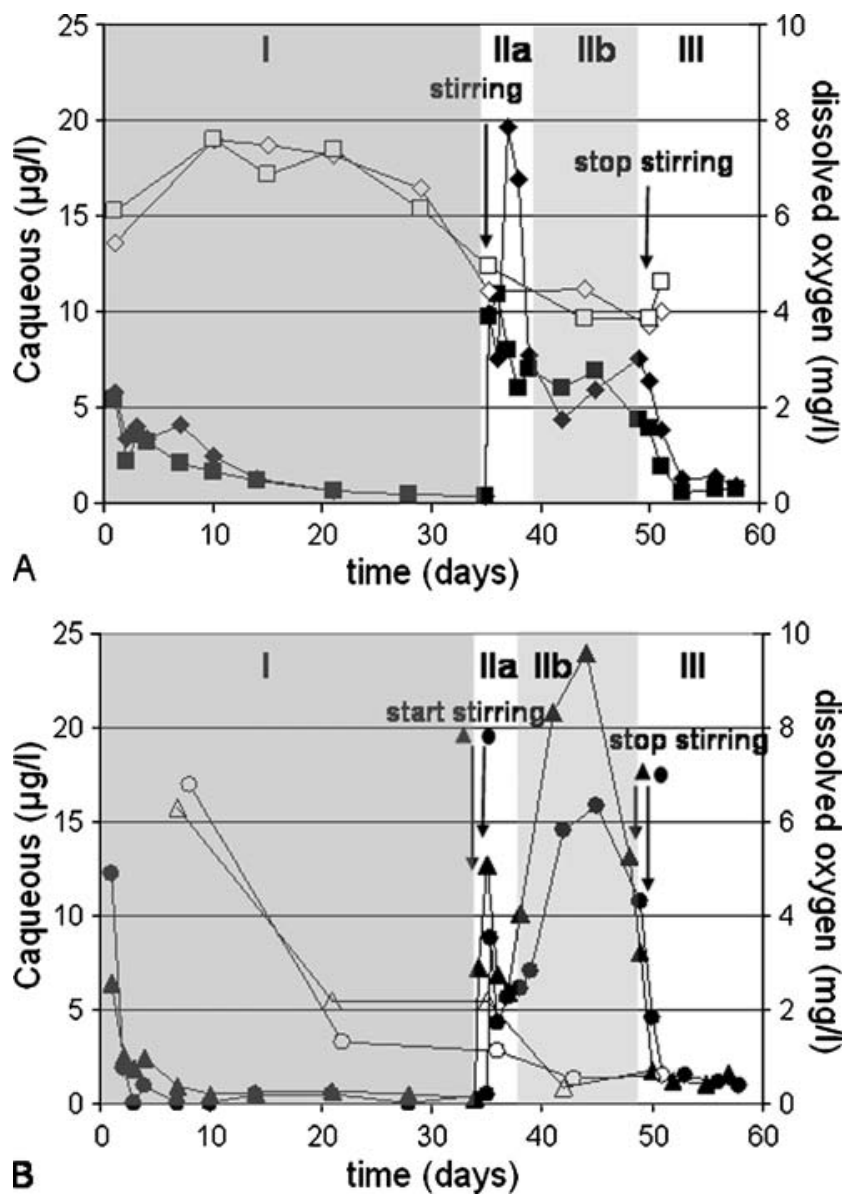

Fig. 3 Nonylphenol concentration in aqueous phase (left $Y$ axis, filled symbols) and dissolved oxygen concentrations (right $Y$ axis, open symbols) during the experiment under a sterile conditions, filled diamond reactor 1 and filled square reactor 2 and $\mathbf{b}$ non-sterile conditions, filled circle reactor 3 and filled triangle reactor 4. Stirring in reactor 4 started 1 day before reactor 3 
concentration in the bulk water in reactor 1 fluctuated between $t=2$ days and $t=7$ days at an average concentration of $3.6 \mu \mathrm{g} 1^{-1}$. Thereafter, between $t=7$ days to $t=35$ days, the NP concentration in the bulk water in this reactor decreased to $0.3 \mu \mathrm{g}^{-1}$. In reactor 2 , the average concentration between $t=2$ days and $t=4$ days was $3.0 \mu \mathrm{g} \mathrm{l}^{-1}$, and a similar decrease to $0.3 \mu \mathrm{g} \mathrm{l^{-1 }}$ was observed at $t=35$ days. As soon as the mixing of the sediment started at $t=35$ days (part IIa), the NP concentration in the bulk water in both sterile reactors increased to a concentration of $9.9 \mu \mathrm{g}^{-1}$ in reactor 1 and $9.7 \mu \mathrm{g} \mathrm{l}^{-1}$ in reactor 2 in the first $8 \mathrm{~h}$ of part IIa. After reaching the maximum concentrations of $19.7 \mu \mathrm{g} 1^{-1}$ and $11.0 \mu \mathrm{g} \mathrm{l^{-1 }}$ in reactors 1 and 2, respectively, the concentration decreased. The NP concentration in the bulk water remained at an average level of $6.4 \pm 1.6 \mu \mathrm{g} \mathrm{l}^{-1}$ in reactor 1 and $6.1 \pm$ $1.2 \mu \mathrm{g} \mathrm{l}^{-1}$ in reactor 2 in part IIb. When the stirring was stopped at $t=49$ days (part III), the NP concentration sharply decreased within 4 days to $0.9 \mu \mathrm{g} \mathrm{l}^{-1}$ and $0.8 \mu \mathrm{g} \mathrm{l^{-1 }}$ in reactors 1 and 2, respectively. This NP concentration was slightly higher compared with the NP concentration at the end of part I. During the sterile experiment, the oxygen concentration remained stable at an average concentration of $6.9 \pm 0.9 \mathrm{mg} \mathrm{l}^{-1}$ and $6.8 \pm 0.7 \mathrm{mg} \mathrm{l}^{-1}$ during the first 29 days in reactors 1 and 2, respectively. During parts IIa and IIb, the dissolved oxygen concentration decreased from 4.4 to $3.7 \mathrm{mg} \mathrm{l}^{-1}$ with a rate of $0.05 \mathrm{mg} \mathrm{l}^{-1} \mathrm{~d}^{-1}$ in reactor 1 and from 4.9 to $3.8 \mathrm{mg} \mathrm{l}^{-1}$ with a rate of $0.07 \mathrm{mg} \cdot \mathrm{l}^{-1} \mathrm{~d}^{-1}$ in reactor 2 . This decrease might be explained from chemical oxidation processes like pyrite oxidation as biodegradation is inhibited by $\mathrm{HgCl}_{2}$ (Vermeulen et al. 2007).

\subsubsection{Non-sterile experiment}

At the start of the non-sterile experiment (reactors 3 and 4), a high initial NP concentration was observed in the bulk water, due to the stirring of the sediment at the start of the experiment (see Fig. 3b; part I). The NP concentration in reactor 3 decreased from $t=1$ day within 1 day to concentrations below the detection limit $\left(100 \mu \mathrm{g}^{-1}\right.$ in the petroleum ether extracts). At $t=4$ days, an NP concentration of $0.9 \mu \mathrm{g} \mathrm{l}^{-1}$ was measured, whereafter the NP concentration fluctuated between $0.5 \mu \mathrm{g} \mathrm{l}^{-1}$ and a concentration below the detection limit. In reactor 4 , the concentration also decreased between $t=1$ and $t=2$ days and remained at an average concentration of $2.2 \pm 0.4 \mu \mathrm{g} \mathrm{l^{-1 }}$ till $t=4$ days (see Fig. 3b; part I). This was followed by a concentration decrease to levels fluctuating between 0.3 and $0.7 \mu \mathrm{g} \mathrm{l}^{-1}$ with the lowest concentration at $t=34$ days, just before stirring. As soon as the mixing of the sediment started (part IIa), the concentration in both reactors increased immediately to an NP concentration of $8.9 \mu \mathrm{g} \mathrm{l}^{-1}$ and $12.7 \mu \mathrm{g}^{-1}$ in reactors 3 and 4, respectively. Subsequently, the concentra- tion decreased in both reactors, but after 2 days of stirring (part IIb) the concentration of NP in the bulk water increased again after 10 days of stirring. Concentrations up to $15.8 \mu \mathrm{g} \mathrm{l}^{-1}$ and $24.0 \mu \mathrm{g} \mathrm{l^{-1 }}$ were measured in reactors 3 and 4 , respectively. The concentrations in both reactors started to decrease just before the mixing was stopped, and this decrease continued in part III, when the settling sediment condition was established again. The average concentration in the bulk water in part III was $1.2 \mu \mathrm{g} \mathrm{l}^{-1}$ and $1.1 \mu \mathrm{g} 1^{-1}$ in reactors 3 and 4 , respectively. The dissolved oxygen concentration during the non-sterile experiment decreased from 6.8 to $1.3 \mathrm{mg} \mathrm{l}^{-1}$ in reactor 3 and from 6.3 to $2.2 \mathrm{mg}^{-1}$ in reactor 4 in part I. The dissolved oxygen concentration decreased further within part IIa and IIb to $0.5 \mathrm{mg} \mathrm{l}^{-1}$ with a rate of $0.1 \mu \mathrm{g} \mathrm{l}^{-1} \mathrm{~d}^{-1}$ and $0.3 \mathrm{~g}^{-1}$ with a rate of $0.3 \mathrm{mg} \mathrm{l}^{-1} \mathrm{~d}^{-1}$ in reactors 3 and 4 , respectively. The decrease of dissolved oxygen in the non-sterile reactors is most probably caused by chemical oxidation processes of sediment minerals and biological processes like organic matter transformation.

\subsection{Mass transfer and biodegradation of NP in reactors}

\subsubsection{Settling sediment conditions (part I)}

For part I, the measured NP concentrations in the bulk water in reactors 1 and 2 showed an exponential decrease in time. The constants $a$ and $b$ of the exponential trend line $\left(\mathrm{C}_{\mathrm{bw}}=a+e^{b \times t}\right)$ and the correlation factor $R^{2}$ are given in Table 2. The data in the first 7 days of the experiment diverged most from the trend line. These data scatter in the beginning of the experiment was also observed in previous performed try out experiments, and this is due to the starting up of the reactors. The mass transfer $(\Phi)$ is calculated using the fitted exponential reduction of the concentration in the bulk water. The $\Phi$ of NP from the sediment to the bulk water is 5.5 and $4.7 \mu \mathrm{g} \mathrm{d}^{-1}$ at the beginning of the experiment in reactors 1 and 2 , respectively, and decreases to $0.3 \mu \mathrm{g} \mathrm{d}^{-1}$ in both reactors at the end of part I. The measured NP concentrations in the bulk water and the mass transfer level off to nearly constant values, which is to be expected according to

Table 2 Constants of exponentional trendline $C_{\mathrm{bw}}=a+e^{b \times t}$, with $C_{\mathrm{bw}}$ as bulk water concentration in micrograms per liter and $t$ as time in days and the correlation coefficients $R^{2}$ of the trend lines

\begin{tabular}{lcc}
\hline Parameters & Reactor 1 & Reactor 2 \\
\hline $\mathrm{a}$ & 5.1 & 3.8 \\
$\mathrm{~b}$ & -0.085 & -0.076 \\
$\mathrm{R}^{2}$ & 0.96 & 0.94 \\
\hline
\end{tabular}


Eq. 2. This indicates that small amounts of NP will continuously desorb from the sediment into the bulk water. A stable mass transfer was not reached yet in our experiments. With a stable mass transfer of NP from sediments to the bulk water, there will be a constant emission of NP from the sediment into the bulk water as long as the pollutant is present in the sediment, even at non-turbulent conditions.

The non-sterile reactors 3 and 4 were operated similar to the sterile reactors 1 and 2 but without the addition of $\mathrm{HgCl}_{2}$. An initial rapid decrease in NP concentration in the aqueous phase is observed. This decrease is not due to biodegradation because the batch experiments with mineral medium showed that the involved microorganisms need a lag phase of at least 2 days before they started to biodegrade NP as shown in Fig. 4. The decrease in concentration in the first 2 days as seen in this figure is not due to biodegradation since this decrease is also observed in the sterile control. The decrease in NP concentration in the reactors in the first day is a result of dilution of the medium after the start up of the experiment, comparable with the sterile reactors 1 and 2 . The measured bulk water concentrations from $t=2$ till $t=21$ days are lower in reactors 3 and 4 than the concentrations measured in the sterile reactors in part I. This lower concentration indicates that the biological activity decreases the NP aqueous concentrations compared with the sterile experiment. This biodegradation of the desorbing NP can take place in the bulk water but is most likely to occur at the aerobic interphase between the anaerobic sediment and the medium because the microorganisms are present in the sediment. The inner part of the sediment was anaerobic. This was confirmed by measurements with the microoxygen electrode, showing that within less than $1 \mathrm{~mm}$ from the top of the sediment oxygen became depleted (results not shown). As the NP concentration decreased

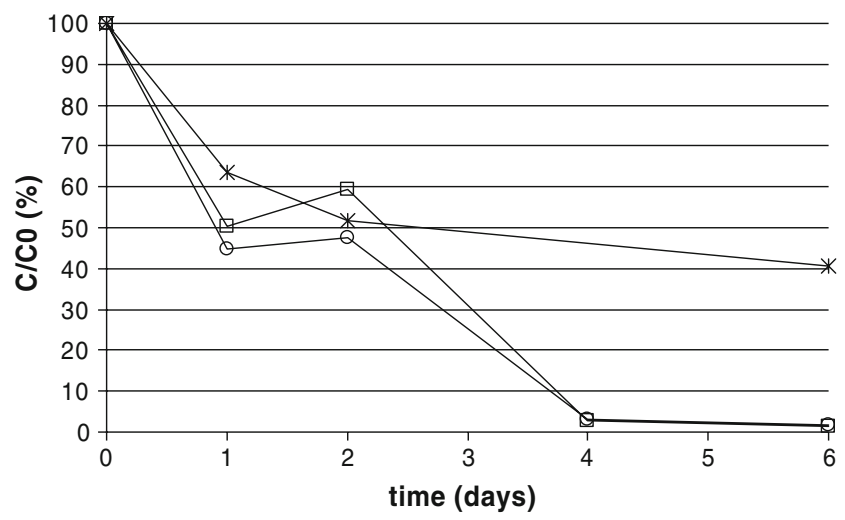

Fig. 4 Relative nonylphenol concentrations during aerobic incubation of sediment from the Huerva River in Spain with medium at $20^{\circ} \mathrm{C}$, open square and open circle are duplicates, and asterisk is a sterile control due to biodegradation, the ecological effects of NP present in the sediment will thus be reduced because the desorbing NP is degraded in this thin interphase before it reaches the bulk water.

At the end of part I, the concentrations in the water phase under sterile and non-sterile conditions were comparable. We had expected lower concentrations in the non-sterile reactors due to biodegradation, but apparently hardly any biodegradation took place at the end of part I. The reason for this reduced biodegradation is most likely due to the low dissolved oxygen concentrations of less than $2.5 \mathrm{mg} \mathrm{l}^{-1}$ in reactors 3 and 4 . This was apparently too low for NP degradation. The oxygen concentration in the non-sterile reactor decreased faster and to a lower concentration compared with the sterile reactor. This difference is caused by biological processes such as the biodegradation of DOC, which needs oxygen as well. As reported in literature, the presence of sufficient oxygen is crucial for NP biodegradation (Ekelund et al. 1993). However, no information is available about preferable oxygen concentrations for NP biodegradation.

\subsubsection{Resuspended sediment conditions (part IIa)}

Directly after mixing of the sediment bed (part IIa), the NP concentration increased in all four reactors. The mass transfer $\Phi$ had a value of $0.3 \mu \mathrm{g} \mathrm{d}^{-1}$ in reactors 1 and 2 before resuspension of the sediment and increased to $29 \mu \mathrm{g} \mathrm{d}^{-1}$ in reactor 1 and $27 \mu \mathrm{g} \mathrm{d}^{-1}$ in reactor 2 in the first $8 \mathrm{~h}$, directly after the first time of resuspending the sediment bed. Two mechanisms explain this sharp increase in mass transfer from the sediment to the bulk water. First, at $t=35$ days when the sediment bed is mixed, the NP in the pores of the sediment is released to the bulk water. The maximum pore water concentration at equilibrium leads to maximum concentrations varying from $1.0 \mu \mathrm{g} \mathrm{l^{-1 }}$ to $3.8 \mu \mathrm{g} \mathrm{l}^{-1}$, based on the lowest and highest reported $K_{\mathrm{d}}$ values obtained for Ebro river sediments (Navarro et al. 2009). The second mechanism is the increase of exchange surface area $\left(A_{\text {sed }}\right)$ in Eq. 1. The surface area of the sediment bed $\left(7.1 \times 10^{-3} \mathrm{~m}^{2}\right)$ is increased about 195 times for $70-\mu \mathrm{m}$ diameter size particles and more than 680 times for $20-\mu \mathrm{m}$ diameter size particles. According to Eq. 1, the mass transfer would increase with a similar factor. In our experiment, the mass transfer increased by a factor of 100. This lower increase is caused by the rapid increase of the concentration in the bulk water $\left(C_{\mathrm{bw}}\right)$ and therefore, a reduction of the driving force of the concentration difference in Eq. 1.

The mass transfer of NP from the sediment to the bulk water under sterile conditions directly after the first time of resuspending the sediment bed ( $t=35$ days) is about three 
times larger than the amount of NP that can be biodegraded under optimal conditions. This is calculated with the product $V \times k \times C$ (Eq. 3), using the first order degradation rate constant of NP of $1.5 \mathrm{~d}^{-1}$ as obtained from the results of the batch experiments with sediment and medium (data not shown). This high mass transfer indicates that resuspension of a sediment bed leads to an immediate increase of the mass transfer of NP to the bulk water due to the release of NP from the pore water and the sediment particles. The released amount of NP cannot be fully degraded and reaches the bulk water.

\subsubsection{Resuspended sediment conditions (part IIb)}

The mass transfer in the sterile reactors during part IIb decreased and levelled off to values of $5.7 \pm 1.9 \mu \mathrm{g} \mathrm{d}^{-1}$ and $5.3 \pm 1.9 \mu \mathrm{g} \mathrm{d}^{-1}$ in reactor 1 and reactor 2 , respectively. This relatively stable mass transfer indicates that a steady state situation has been reached. However, the system is not at equilibrium yet, because the equilibrium concentration in the water phase should be between 11 and $44 \mu \mathrm{g} \mathrm{l}^{-1}$, calculated with the range of $K_{\mathrm{d}}$ values (Navarro et al. 2009), which is higher than the average bulk water concentration of 6.4 and $6.1 \mu \mathrm{g}^{-1}$ reactors 1 and 2, respectively. The mass transfer in part IIb is significantly higher compared with the mass transfer at the end of part I. This is to be expected since the contact area of the sediment particles with the bulk water is much larger during stirring compared with the contact area in the presence of a sediment bed.

In the non-sterile reactors, a decreased mass transfer of NP to the bulk water was expected, as part of the NP should be biodegraded. However, in part IIb of the non-sterile reactor, a second increase in mass transfer is observed instead of a constant mass transfer as seen in the sterile reactors. This second increase in mass transfer seems to be related to microbial activity because the sterile and nonsterile reactors are operated equally, and this phenomenon is not observed under sterile conditions. What kind of microbial processes results in this second increase of NP mass transfer is not clear.

From the results of the NP concentrations in the nonsterile reactors during the resuspension in part IIb, we cannot derive to what extent the extra released NP is degraded. However, the NP seemed not to be biodegraded at the end of part I due to low oxygen concentrations. The oxygen concentration during part IIa and IIb decreased further, which indicates that no or almost no NP could be biodegraded during part IIb. Therefore, the product $V \times k \times C$ for biodegradation in Eq. 3 can be assumed to be negligible. The maximum mass transfer in the non-sterile reactors during part IIa was $16 \mu \mathrm{g} \mathrm{d}^{-1}$ and $21 \mu \mathrm{g} \mathrm{d}^{-1}$ after 7 days of stirring in reactors
3 and 4, respectively, which is comparable to the amount of NP that could have been degraded as calculated with the product $V \times k \times C$ (Eq. 3) under optimal conditions for biodegradation. This indicates that, although more NP desorbs from the sediment under non-sterile conditions than under sterile conditions during longer periods of resuspension of the sediment, this extra released NP can be degraded under optimal environmental conditions for biodegradation.

In field situations, the conditions are often not optimal for biodegradation and the desorbing NP may not be fully degraded. For example, the temperatures in river basins are often lower than the $20^{\circ} \mathrm{C}$ and do not stay constant as used in this experiment. Lower temperatures will lead to lower biodegradation rates. Also, the river water can be less optimal for biodegradation compared with the medium which was used. This was observed in batch experiments with sediment and river water. Slightly less efficient biodegradation was observed in batch experiments performed with sediment and river water. Nonylphenol was degraded in the presence of the river water of the same location as the sediment originates from; however, the complete degradation was slower. In duplicate batches with river water, it took 8 days to almost completely biodegrade NP (89\%), whereas in the duplicate batches with medium, the NP was almost completely degraded (97\%) in less than 4 days (data not shown). Thereby, in our experiments, the flow rate was kept at $0.7 \mathrm{ml} \mathrm{min}^{-1}$, also during the resuspension of the sediment, to avoid a wash out of the microorganisms. During a flood event in the field, the flow rate will be much higher, which results in larger concentration gradients between the sediment particles and bulk water. This larger gradient may lead to a higher mass transfer than measured in our reactor experiments. However, higher flow and refreshment of the water also leads to higher dissolved oxygen concentrations, which make the circumstances for biodegradation of NP more optimal.

\subsubsection{Resumed settling sediment conditions (part III)}

After the stirring was stopped (part III), the concentrations decreased in all four reactors as expected because $A_{\text {sed }}$ decreased, and the sediment bed was established again. The comparable concentrations in the non-sterile and sterile reactors in part III indicate that no biodegradation took place after stirring, probably caused by the low dissolved oxygen concentrations in the non-sterile reactors, which had been dropped further during the resuspension period to $0.7 \mathrm{mg}^{-1}$. With higher flow rates, which often occur in field situations after floodings, more oxygen will be present and the biodegradation will continue, as had occurred in the beginning of part I. 


\subsection{Mass balance of concentration in sediment}

Before and after the experiments, the concentration of NP in the sediment $\left(C_{\mathrm{sed}}\right)$ was measured. At the end of the sterile reactor experiment, $72 \%$ and $64 \%$ of the original NP was present in the sediment in reactors 1 and 2, respectively (Fig. 5). From the desorbed NP, $62 \pm 1 \%$, was released during the resuspension of the sediment (parts IIa and IIb). Under non-sterile conditions, $56 \%$ and $47 \%$ of the original present NP remained in the sediment in reactors 3 and 4, respectively. This significant difference of NP concentration in the sediments at the end of the sterile and non-sterile experiments is caused by the biodegradation of the released NP during part I and the extra mass transfer of NP during part IIb under non-sterile conditions.

The NP in the sediment is potentially available for $95 \%$ including a rapidly desorbing fraction of $75 \%$ as determined by direct mixed sediment-Tenax extractions (de Weert et al. 2008). Based on the reactor experiments, we calculated that it will take 5 years for the rapid available fraction to be desorbed from the sediment under non-sterile conditions, as long as the sediment is present in a settled bed. With higher flow rates, compared with the flow rate in our experiment, this will probably be faster because of the larger concentration gradient between the sediment particles and the bulk water. Nevertheless, this is only for the particles at the surface of the sediment bed and not for the particles in deeper layers of the bed. During resuspension, the NP is released faster compared with the sediment present in a bed. In our experiment, it will take 30 days before the rapidly desorbing fraction is released, as calculated with the maximum mass transfer of NP from the sediment to the water phase during resuspension under non-sterile conditions. However, in the experiments, the flow was kept low, and in field situations, the flow will increase during a flooding. This increase in flow will decrease the concentration of NP in the bulk water which results in a faster desorption of NP from the sediment to the bulk water.

The sediment which was used in this experiment was highly contaminated with NP which was also completely available. The sediment originated from the Huerva river. We could not find a particular reason for this high NP concentration. Although the NP concentration of our sediment is about ten times higher than most concentrations found in sediments of other rivers, this concentration is not an exception. In sediment of lakes and rivers in Canada, Japan and China, comparable concentrations are measured (Isobe et al. 2001; Bennie et al. 1997; Wu et al. 2007). This makes the results of our experiment relevant for other sediments and locations.

\subsection{Perspectives of other estrogenic compounds}

In this study, we used NP as a model compound for aerobically biodegradable estrogenic compounds. Previously we have shown that NP has the same availability and biodegradation behaviour as the total mixture of other predominantly unknown estrogenic compounds in this sediment. This was assessed by measuring estrogenic activities before and after aerobic treatment of the sediment (de Weert et al. 2008). From the results from the reactor experiments with $\mathrm{NP}$ and our previous study, it can be expected that other estrogenic compounds present in this sediment will also desorb and be degraded like NP. In addition, a similar increased mass transfer to the bulk water during resuspension, as found for NP, can be expected for these other estrogenic compounds. As these estrogenic compounds generally also need oxygen for their degradation, oxygen depletion by processes such as eutrophication and degradation of organic matter (Paerl et al. 1998; Smith et al. 1999;
Fig. 5 Relative NP concentration in the sediment at the start $\left(C_{0}\right)$ and the end $\left(C_{\mathrm{e}}\right)$ of the reactor experiments. $\square=C_{0}$, $\square=C_{\mathrm{e}}$ reactor $1, \square=C_{\mathrm{e}}$ reactor $2, \quad=C_{\mathrm{e}}$ reactor 3 , $\square=C_{\mathrm{e}}$ reactor 4

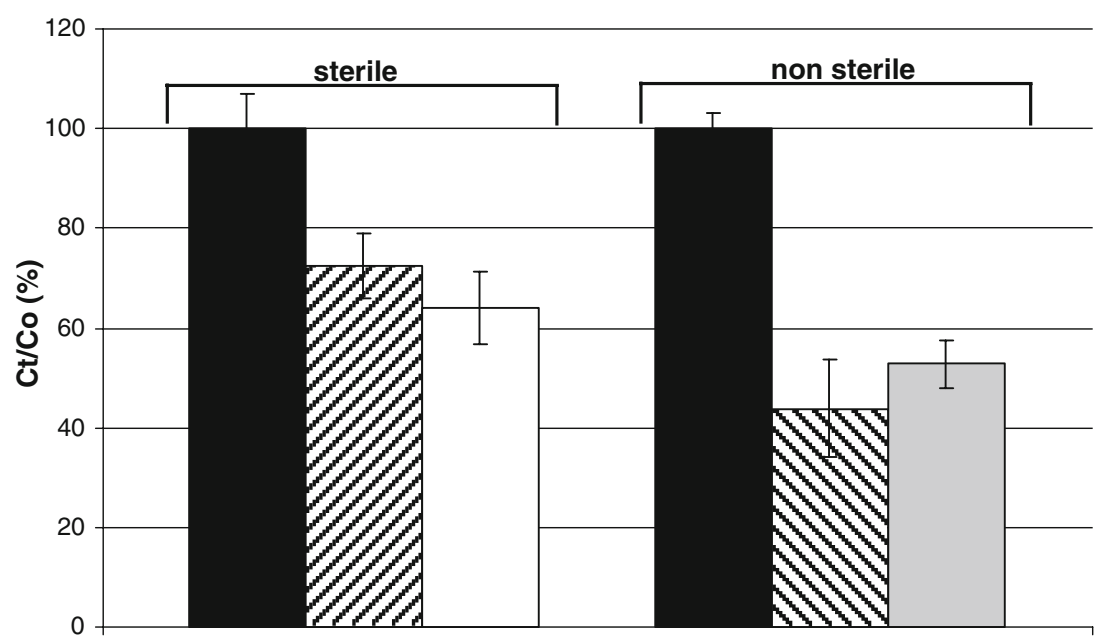


Taft et al. 1980) lead to an increased estrogenic compound concentration in bulk river water because biodegradation cannot counter balance the desorption and mass transfer. More estrogenic compounds will enter the bulk water during resuspension than when the sediment is present in a sediment bed. The released estrogenic compounds can potentially cause estrogenic effects, especially upon sediment resuspension combined with low oxygen or (temporary) anoxic conditions. Therefore, anoxic conditions should be prevented to reduce the risk of these estrogenic compounds for the organisms in the aquatic systems.

\section{Conclusions}

From our reactor experiments, it can be concluded that the experimental setup can be used to study combined processes of NP desorption and NP biodegradation. Under settling sediment conditions, a continuous amount of NP is transferred from the sediment bed to the bulk water. Biodegradation reduces the NP concentrations in the bulk water by counter balancing desorption and mass transfer from the sediment bed to the bulk water. When changing to resuspended sediment conditions, the mass transfer of NP to the bulk water initially increases sharp under sterile and non-sterile conditions due to the release of NP from pore water and enlargement of the sediment desorption area. This initial mass transfer is larger than the amount of NP that can be biodegraded with the optimal biodegradation rate. Therefore, resuspension can lead to an initial increased concentration. After 2 days of resuspending the sediment, more NP is released under non-sterile conditions than under sterile conditions due to biological processes most likely affecting the adsorption properties of the sediment. The mass transfer becomes comparable to the amount of NP that can be biodegraded with an optimal biodegradation rate during a longer period of resuspension under non-sterile conditions. Finally we expect that the desorbing concentrations can be reduced during longer periods of resuspension by biodegradation if the environmental conditions are optimal for biodegradation. Therefore, the environmental parameters should be optimised and especially, sufficiently high dissolved oxygen concentrations are important.

\begin{abstract}
Acknowledgements This research was financially supported by the EU FP6 Aquaterra (project number 505428 GOCE). The authors want to thank Harry Brunning of the Department of Environmental Technology of Wageningen University, The Netherlands for his contribution to the interpretation of the data.
\end{abstract}

Open Access This article is distributed under the terms of the Creative Commons Attribution Noncommercial License which permits any noncommercial use, distribution, and reproduction in any medium, provided the original author(s) and source are credited.

\section{References}

Bennie DT, Sullivan CA, Lee H-B, Peart TE, Maguire RJ (1997) Occurrence of alkylphenols and alkylphenol mono- and diethoxylates in natural waters of the Laurentian Great Lakes basin and the upper St. Lawrence River. Sci Total Environ 193:263-275

Birdwell J, Cook RL, Thibodeaux LJ (2007) Desorption kinetics of hydrophobic organic chemicals from sediment to water: a review of data and models. Environ Toxicol Chem 26:424434

Brown JF, Wagner RE, Feng H, Bedard DL, Brennan MJ (1987) Environmental dechlorination of PCBs. Environ Toxicol Chem 6:579-593

Buurman P, Pape T, Muggler CC (1997) Laser grain-size determination in soil genetic studies 1. Practical problems. Soil Sci 162:211-218

Cheng C-Y, Atkinson JF, DePinto JV (1995) Desorption during resuspension events: kinetic v. equilibrium model. Mar Freshwater Res 46:251-256

Corvini PFX, Schäffer A, Schlosser D (2006) Microbial degradation of nonylphenol and other alkylphenols-our evolving review. Appl Microbiol Biotechnol 72:223-243

de Mes T, Zeeman G, Lettinga G (2005) Occurrence of estrone, 17 beta-estradiol, and 17 alfa-ethynylestradiol in STPs for domestic wastewater. Rev Environ Sci BioTechnol 4:275- 311

de Weert J, De la Cal A, van den Berg H, Murk AJ, Langenhoff AAM, Rijnaarts HHM, Grotenhuis JTC (2008) Bioavailability and biodegradation of nonylphenol in sediment determined with chemical and bioanalysis. Environ Toxicol Chem 27:778-785

Ekelund R, Granmo A, Magnusson K, Berggren M (1993) Biodegradation of 4-nonylphenol in seawater and sediment. Environ Poll 79:59-61

Gibson CA, Meyer JL, Poff NL, Hay LE, Georgakakos A (2005) Flow regime alterations under changing climate in two river basins: implications for freshwater ecosystems. River Res Applic 21:849-864

Heemken OP, Reincke H, Stachel B, Theobald N (2001) The occurrence of xenoestrogens in the Elbe River and the North Sea. Chemosphere 45:245-259

Huttunen JT, Väisänen TS, Helsten SK, Martikainen PJ (2006) Methane fluxes at the sediment-water interface in some boreal lakes and reservoirs Boreal. Environ Res 11:27-34

Isobe T, Nishiyama H, Nakashima A, Takada H (2001) Distribution and behaviour of nonylphenol, octylphenol, and nonylphenol monoethoxylate in Tokyo metropolitan area: their association with aquatic particles and sedimentary distributions. Environ Sci Technol 35:1041-1049

Martin P, Granina L, Materns K, Goddeeris B (1998) Oxygen concentration profiles in sediments of two ancient lakes: Lake Baikal (Siberia, Russia) and Lake Malawi (East Africa). Hydrobiol 367:163-174

Middeldorp P, Staps S, Rijnaarts HHM, Roelofsen F, Valstar J, Smits J (2003) Natural attenuation of organic contaminants at the interface between groundwater and surface water. ICC Gent, Belgium

Mohn WM, Tiedje JM (1992) Microbial reductive dehalogenation. Microbiol Rev 56:482-507

Navarro A, Endo S, Gocht T, Barth JAC, Lacorte S, Barcelo D, Grathwohl P (2009) Sorption of alkylphenols on Ebro River sediments: comparing isotherms with field observations in river water and sediments. Environ Poll 157:698-703

Paerl HW, Pinckney JL, Fear JM, Peierls BL (1998) Ecosystem responses to internal and watershed organic matter loading: consequences for 
hypoxia in the eutrophying Neuse River Estuary, North Carolina, USA. Mar Ecol Prog Ser 166:17-25

Smit M, Grotenhuis JTC, Bruning H, Rulkens W (2008) Desorption of dieldrin from field aged sediments: simulating flood events. J Soils Sediments 8:80-85

Smith VH, Tilman GD, Nekola JC (1999) Eutrophication: impacts of excess nutrient inputs on freshwater, marine, and terrestrial ecosystems. Environ Poll 100:179-196

Soares A, Guieysse B, Jefferson B, Cartnell E, Lester JN (2008) Nonylphenol in the environment: a critical review on occurrence, fate, toxicity and treatment in waste waters. Environ Int 34:10331049

Taft JL, Taylor WR, Hartwig EO, Loftus R (1980) Seasonal oxygen depletion in Chesapeake Bay. Estuaries 3:242-247

Tros ME, Schraa G, Zehnder AJB (1996) Transformation of low concentrations of 3-chlorobenzoate by Pseudomonas sp. strain B13; kinetics and residual concentrations. Appl Environ Microbiol $62: 437-442$
Vermeulen J, Grotenhuis JTC, Joziasse J, Rulkens W (2003) Ripening of clayed dredged sediments during temporary upland disposal: a bioremediation technique. J Soils Sediments 3:49-59

Vermeulen J, van Gool MPM, Dorleijn AS, Joziasse J, Bruning H, Rulkens W, Grotenhuis JTC (2007) Biochemical ripening of dredged sediments. Part 1. Kinetics of biological organic matter mineralization and chemical sulfur oxidation. Environ Toxicol Chem 26:2530-2539

Vink JPM (2002) Measurement of heavy metal speciation over redox gradients in natural water-sediment interphases and implications for uptake by benthic organisms. Environ Sci Technol 23:5130-5138

Vink JPM, Harmsen J, Rijnaarts HHM (2009) Delayed immobilization of heavy metals in sediments under reducing and anaerobic conditions; consequences for storage and permanent inundation. Appl Geochem. In press

Wu ZB, Zhang Z, Chen SP, He F, Fu GP, Liang W (2007) Nonylphenol and octylphenol in urban eutrophic lakes of subtropical China. Fresenius Environ Bull 16:227-234 